\title{
Blepharoptosis among Korean adults: age- related prevalence and threshold age for evaluation
}

\author{
Ji-Sun Paik', Kyungdo Han², Suk-Woo Yang ${ }^{3^{*}}$ D, Yongkyu Park ${ }^{2^{*}}$, Kyungsun Na' ${ }^{1}$, Wonkyung Cho ${ }^{4}$, \\ Su-Kyung Jung ${ }^{5}$ and Sungeun Kim $^{3}$
}

\begin{abstract}
Background: To evaluate the prevalence of blepharoptosis among Korean adults and the characteristics of blepharoptosis patients, and to determine an appropriate age threshold for recommending blepharoptosis evaluation.

Methods: The Korean National Health and Nutrition Examination Survey (KNHANES-V) was conducted in 20102012. We extracted data on 17,878 Korean adults aged more than and equal to 19 years included in KNHANES-V, and determined blepharoptosis prevalence according to age, to determine the cutoff age for recommending blepharoptosis evaluation. We also determined the possible association between blepharoptosis and obesity parameters, such as body mass index (BMI) and waist circumference (WC).

Results: There was astrong association between older age and the prevalence of blepharoptosis. The cutoff age for recommending blepharoptosis evaluation was 63 years for males, 70 years for females, and 66 years for all patients. Patients with a high BMI and large WC had a higher prevalence of blepharoptosis in all age groups except for those aged over 80 years. The association of blepharoptosis with BMI according to age group showed that in the 50-59 and 60-69 years age groups, blepharoptosis prevalence and BMI were higher. However, in the 70-79 and 80-89 years age groups, extremely obese patients (BMI > 30) showed a decreased blepharoptosis prevalence.

Conclusions: Moderate to severe blepharoptosis can result in poor visual function and exacerbate headaches and depression, leading to decreased quality of life. This study proposed an appropriate age threshold for recommending evaluation of patients with blepharoptosis among the general population of Korea.
\end{abstract}

Keywords: Blepharoptosis, Korean population, Age-related prevalence, Threshold age

\section{Background}

Blepharoptosis, which refers to the drooping of one or both eyelids, affects both the function and appearance of the eyes [1]. In aponeurotic blepharoptosis, the levator aponeurosis and the underlying Müller's muscle are detached from the tarsus, attenuated in functional terms, and elongated due to the aging process or other mechanisms [2-4]. As a result, droopiness of the eyelids may

\footnotetext{
* Correspondence: yswoph@catholic.ac.kr; ygpark@catholic.ac.kr ${ }^{3}$ Department of Ophthalmology and Visual Science, Seoul St. Mary's Hospital, College of Medicine, The Catholic University of Korea, 222 Banpo-daero, Seocho-Gu, Seoul 137-701, South Korea

2Department of Biostatistics, The Catholic University of Korea, 222 Banpo-daero, Seocho-Gu, Seoul 137-701, South Korea

Full list of author information is available at the end of the article
}

interfere with the superior visual field and, in moderate to severe cases, the central visual field [3, 4]. Blepharoptosis also results in an altered facial appearance, with patients reporting that they looked "tired" and "more aged." Following ptosis repair surgery, patients ranked eye and eyelid appearance as the most important postoperative changes with respect to their improved visual field [5].

Psychological distress has been reported to be associated with the presence of blepharoptosis. Richards et al. reported that patients with blepharoptosis had higher levels of anxiety, depression, and concerns regarding their appearance than the general population [5]. When questioned about their visual function-related quality of life, Briceño et al. reported that after surgery for ptosis

(c) The Author(s). 2020 Open Access This article is distributed under the terms of the Creative Commons Attribution 4.0 International License (http://creativecommons.org/licenses/by/4.0/), which permits unrestricted use, distribution, and reproduction in any medium, provided you give appropriate credit to the original author(s) and the source, provide a link to the Creative Commons license, and indicate if changes were made. The Creative Commons Public Domain Dedication waiver (http://creativecommons.org/publicdomain/zero/1.0/) applies to the data made available in this article, unless otherwise stated. 
repair, patients reported a significant increase in visual function [6]. Based on these findings, physicians should be concerned about appearance-related distress and compromised psychological well-being among patients with ptosis.

Droopiness of the eyelids can also lead to reflexive contraction of the occipitofrontalis muscle in patients with ptosis. As a result of tonic reflexive contraction of the occipitofrontalis muscle, ptosis patients may also experience tension-related headaches [7-9]. Similarly, Simsek reported that surgery for ptosis and blepharoptosis provided significant relief from tension-related headaches, and resulted in an improved quality of life [10].

Involutional blepharoptosis is a result of the aging process combined with periorbital changes [11], and can precipitate functional [6] and psychological distress [4] and certain types of severe headache [7-9]. All blepharoptosis symptoms can usually be controlled by surgery to remove excessive upper eyelid skin and reinforce the levator apouneurosis [12]. This study is the first to assess the prevalence of involutional blepharoptosis according to age in a representative Korean population. We also determined the possible relationship between blepharoptosis and obesity by age group. Overall, the purpose of this study was to determine an appropriate age threshold for recommending evaluation for blepharoptosis among Korean adults.

\section{Methods}

\section{Survey and subjects}

This study used data from the Korean National Health and Nutrition Examination Survey (KNHANES-V), which was performed in 2010-2012 by the Korean Centers for Disease Control and Prevention and the Korean Ministry of Health and Welfare, Sejong, Republic of Korea. A total of 25,534 individuals in KNHANES-V were identified as candidates for this study. Participants aged less than 19 years $(n=5935)$ were excluded, as were adults with a previous history of eyelid or intraocular surgery, or with a medical condition that might affect the position of the eyelid or motility, including thyroid disease, systemic collagen disease, myopathy, cerebrovascular and cardiovascular disease $(n=1721)$. Nonoperated adult patients with congenital blepharoptosis were included in this study. In total, 17,878 adults were included in the final analyses. All participants provided written consent forms prior to enrollment. The Institutional Review Board of the Korea Centers for Disease Control and Prevention (KCDC) reviewed and approved this nationally representative data study.

\section{Sociodemographic and lifestyle variables}

Trained interviewers from the KNHANES-Vadministered standardized health examinations and questionnaires. Current smokers were defined as participants who currently smoked and had smoked more than 100 cigarettes in their lifetime. Participants were also categorized based on the quantity of alcohol consumed per day for the month prior to the interview; participants were considered heavy drinkers if they had consumed more than $30 \mathrm{~g}$ per day. Participants who performed moderate exercise at least five times per week for $30 \mathrm{~min}$ or more per session, or who performed vigorous exercise at least three times per week for $20 \mathrm{~min}$ or more per session, were considered regular exercisers. The educational level was classified as high if the respondent had completed a high school education. A monthly household income of less than 1092.40 United Sates dollars (USD) corresponded to the lowest income quartile.

\section{Anthropometric and biochemical measurements}

Anthropometric measurements were performed by specially trained examiners. Body weight and height, measured with participants barefoot and wearing light clothing, were used to calculate the body mass index (BMI). Waist circumference (WC) was estimated to the nearest $0.1 \mathrm{~cm}$ in a horizontal plane at the midpoint from the iliac crest to the costal margin at the end of a normal expiration. Blood pressure was checked every $8 \mathrm{~h}$ via the right arm while the participant was in a sitting position, after about $5 \mathrm{~min}$ of relaxation, by a mercury sphygmomanometer (Baumanometer; Baum, Copiague, NY, USA). The definitive blood pressure was determined using mean values of the second and third measurements. A participant was classified as hypertensive if the systolic blood pressure was more than $140 \mathrm{mmHg}$ or the diastolic blood pressure was more than $90 \mathrm{mmHg}$, or if the participant had been diagnosed with high blood pressure and was taking high blood pressure medication. The percent body fat (fat mass/total mass $\times 100, \%$ ) and sum of the lean soft tissue mass of the arms and legs were obtainedby dual-energy X-ray absorptiometry (DXA, QDR 4500 A; Hologic, Waltham, MA, USA) at mobile examination centers.

\section{Blepharoptosis definitions}

The eyelid positions of all participants were examined by specially trained opticians who were resident physicians. The qualitycontrol of the ophthalmic survey was performed by the Epidemiologic Survey Committee of the Korean Ophthalmologic Society. Marginal reflex distance 1 (MRD1) was defined as the distance from the upper eyelid margin to the corneal light reflex in the primary position $[13,14]$. The ophthalmic resident physicians with over 3 years of experience participated in this survey by directly measuring with a ruler. A differential diagnosis of blepharoptosis was made with particular attention paid to pseudoptosis associated with eyebrow ptosis and dermatochalasis. MRD1 values were obtained and sorted into five subclassifications: (1) $\geq 4.0 \mathrm{~mm}$, (2) $3.0-3.9 \mathrm{~mm}$, (3) 2.0 
$2.9 \mathrm{~mm}$, (4) $1.0-1.9 \mathrm{~mm}$, and $(5)<1.0 \mathrm{~mm}$. Before data analyses, we defined blepharoptosis as an MRD1 of less than $2 \mathrm{~mm}$ for either eye. The levator function test (LFT) was also evaluated by measuring the upper eyelid excursion from downgaze to upgaze, excluding any influence of frontalis muscle function, and sorted into four subclassifications: (1) $\geq 12 \mathrm{~mm}$, (2) $8-11 \mathrm{~mm}$, (3) $5-7 \mathrm{~mm}$, and $(4)<4 \mathrm{~mm}$

\section{Statistical analysis}

Statistical analyses were conducted using the survey procedure of SAS Windows software (version 9.3; SAS Institute, Cary, NC, USA) to account for the complex sampling design from the KNHANES, which supplies nationally representative blepharoptosis prevalence estimated values. A two-sided $P$ value less than 0.05 was considered statistically important. Fundamental characteristics of participants with and without blepharoptosis were expressed as proportions (\% standard error, SE) for categorical variables and as means \pm SE for continuous variables. The chi-square test or independent twosample $t$-test was performed to compare differences in participant characteristics with or without the presence of blepharoptosis. The cutoff age in the prediction of blepharoptosis was defined as the point of largest statistical value by the Rao-Scott chi-square test.

\section{Results}

General characteristics of the study participants (Table 1) The baseline characteristics of the study participants are presented in Table 1. The cross-sectional analyses included data on 17,878 adults $(15,178$ participants without blepharoptosis and 2160 participants with blepharoptosis). Among the eligible participants, the incidence of blepharoptosis was $12.08 \%$. Table 1 shows the results of univariate analyses of the associations between blepharoptosis and demographic characteristics, lifestyle and medical factors, and obesity parameters. Based on univariate analyses, factors associated with the composite outcome of blepharoptosis were less drinking, less exercise, less income, less education, more metabolic syndromes, more hypertension, more severe diabetes, more cataracts, less employment, higher age, a higher BMI, and a greater WC. After adjusting for confounders, age, and obesity parameters including BMI and WC were closely related with blepharoptosis.

\section{Eyelid measurements and blepharoptosis prevalence according to age group (Table 2 and Fig. 1 )}

Table 2 shows the mean MRD1 (mm) and mean levator function test (LFT, mm) results for both eyes and for all age groups, as well as the blepharoptosis prevalence (\%) according to age group. Both mean the MRD1 and mean LFT decreased, while blepharoptosis prevalence (\%) increased, with increasing age. These relationships were especially apparent in the group over 60 years of age. Figure 1 shows the prevalence (\%) of blepharoptosis for male, female, and all participants according to age group. Generally, blepharoptosis prevalence increased with increasing age, and increased more rapidly between the 50-59 and 60-69 years of age groups, and between the 60-69 and 70-79 years of age male, female, and total participants, because the slope of line was steeper in these sections compared to the other sections.

Table 1 The baseline characteristics of the studied individuals with or without blepharoptosis

\begin{tabular}{|c|c|c|c|}
\hline & \multicolumn{2}{|l|}{ Blepharoptosis } & \multirow[t]{2}{*}{$P$} \\
\hline & No $(n=15,718)$ & Yes $(n=2160)$ & \\
\hline Smoke & $23.8(0.5)$ & $22.1(1.3)$ & 0.238 \\
\hline Alcohol drinking & $59.5(0.6)$ & $47.1(1.5)$ & $<0.0001$ \\
\hline Exercise & $19.9(0.5)$ & $16.2(1.3)$ & 0.0069 \\
\hline Low income & $14.7(0.5)$ & $33.4(1.6)$ & $<0.0001$ \\
\hline Education level (over high school) & $74.2(0.7)$ & $33.8(2.0)$ & $<0.0001$ \\
\hline Metabolic syndrome & $23.9(0.5)$ & $46.7(1.4)$ & $<0.0001$ \\
\hline Hypertension & $24.8(0.5)$ & $51.2(1.6)$ & $<0.0001$ \\
\hline Diabetes & $7.3(0.3)$ & $19.6(1.1)$ & $<0.0001$ \\
\hline Cataract & $22.6(0.7)$ & $63.5(2.0)$ & $<0.0001$ \\
\hline Family history of ocular disease & $20.9(0.5)$ & $14.1(1.1)$ & $<0.0001$ \\
\hline Occupation & $65.4(0.5)$ & $53.5(1.5)$ & $<0.0001$ \\
\hline Age & $43.9 \pm 0.2$ & $60.5 \pm 0.7$ & $<0.0001$ \\
\hline Body mass index & $23.6 \pm 0.04$ & $24.3 \pm 0.09$ & $<0.0001$ \\
\hline Waist circumstance & $80.7 \pm 0.1$ & $84.5 \pm 0.3$ & $<0.0001$ \\
\hline
\end{tabular}


Table 2 Eyelid parameters including MRD1 and LFT according to age group

\begin{tabular}{|c|c|c|c|c|c|c|c|c|}
\hline & Number & Age group & & & & & & \\
\hline & & $<30$ & 30-39 & $40-49$ & $50-59$ & $60-69$ & 70-79 & $\geq 80$ \\
\hline & & 2072 & 3248 & 3133 & 3421 & 3066 & 2399 & 539 \\
\hline Right MRD1\% (SE $)$ & $\geq 4 \mathrm{~mm}$ & $52.36(2.08)$ & $52.13(1.78)$ & $46.45(1.85)$ & $32.76(1.66)$ & $21.69(1.42)$ & $11.86(1.15)$ & $7.65(1.71)$ \\
\hline & $3-3.9 \mathrm{~mm}$ & $32.13(1.70)$ & $33.97(1.47)$ & $34.13(1.44)$ & $38.13(1.44)$ & $33.74(1.38)$ & $28.50(1.56)$ & $23.15(2.30)$ \\
\hline & $2-2.9 \mathrm{~mm}$ & $12.97(1.23)$ & $10.92(0.98)$ & $15.65(1.51)$ & $20.56(1.16)$ & $25.67(1.20)$ & $31.03(1.36)$ & $30.40(2.57)$ \\
\hline & $1-1.9 \mathrm{~mm}$ & $2.08(0.41)$ & $2.53(0.42)$ & $3.10(0.41)$ & $7.05(0.69)$ & $13.87(0.99)$ & $20.47(1.22)$ & $23.11(2.33)$ \\
\hline & $<1 \mathrm{~mm}$ & $0.46(0.16)$ & $0.46(0.15)$ & $0.68(0.20)$ & $1.50(0.27)$ & $5.03(0.64)$ & $8.15(0.82)$ & $15.69(2.31)$ \\
\hline Left MRD1\% (SE) & $\geq 4 \mathrm{~mm}$ & $52.38(2.06)$ & $52.21(1.77)$ & $46.68(1.86)$ & $32.92(1.67)$ & $21.49(1.43)$ & $11.89(1.16)$ & $7.35(1.70)$ \\
\hline & $3-3.9 \mathrm{~mm}$ & 31.69 (1.68) & $33.39(1.47)$ & $34.01(1.42)$ & $37.92(1.39)$ & $33.78(1.45)$ & $28.95(1.60)$ & $22.83(2.32)$ \\
\hline & $2-2.9 \mathrm{~mm}$ & $13.26(1.27)$ & $11.05(0.98)$ & $15.34(1.51)$ & $20.37(1.16)$ & $20.37(1.21)$ & $29.95(1.35)$ & $29.76(2.48)$ \\
\hline & $1-1.9 \mathrm{~mm}$ & $2.33(0.44)$ & $2.86(0.43)$ & $3.31(0.44)$ & $7.48(0.66)$ & $13.25(1.00)$ & $21.13(1.29)$ & $24.15(2.33)$ \\
\hline & $<1 \mathrm{~mm}$ & $0.35(0.14)$ & $0.49(0.15)$ & $0.58(0.17)$ & $1.30(0.26)$ & $5.19(0.67)$ & $8.08(0.86)$ & 15.93 (2.06) \\
\hline Rigth LFT \% (SE) & $\geq 12 \mathrm{~mm}$ & 81.47 (1.48) & $81.13(1.44)$ & 74.31 (1.62) & 63.51 (1.59) & $47.73(1.73)$ & $32.50(1.84)$ & $23.67(2.62)$ \\
\hline & $8-11 \mathrm{~mm}$ & $17.86(1.45)$ & $17.97(1.36)$ & $24.51(1.58)$ & 33.70 (1.52) & $45.43(1.61)$ & $54.07(1.81)$ & $55.22(2.68)$ \\
\hline & $5-7 \mathrm{~mm}$ & $0.67(0.22)$ & $0.89(0.34)$ & $0.95(0.23)$ & $2.52(0.41)$ & $5.68(0.67)$ & $11.84(1.03)$ & $16.91(2.13)$ \\
\hline & $<4 \mathrm{~mm}$ & - & $0.02(0.02)$ & $0.23(0.15)$ & $0.28(0.15)$ & $1.17(0.47)$ & $1.60(0.49)$ & $4.20(1.73)$ \\
\hline Left LFT \% (SE) & $\geq 12 \mathrm{~mm}$ & $81.91(1.46)$ & 81.75 (1.43) & $74.92(1.60)$ & $64.55(1.55)$ & $47.90(1.75)$ & 32.68 (1.84) & $23.48(2.66)$ \\
\hline & 8-11 mm & $17.35(1.42)$ & $17.30(1.36)$ & $23.74(1.56)$ & 32.29 (1.45) & $45.58(1.61)$ & $54.00(1.73)$ & $56.10(2.74)$ \\
\hline & $5-7 \mathrm{~mm}$ & $0.74(0.27)$ & $0.93(0.34)$ & $1.11(0.26)$ & $2.87(0.44)$ & $5.38(0.67)$ & 11.89 (1.06) & $15.74(2.08)$ \\
\hline & $<4 \mathrm{~mm}$ & - & $0.02(0.02)$ & $0.23(0.11)$ & $0.28(0.15)$ & $1.14(0.47)$ & $1.44(0.48)$ & $4.68(1.77)$ \\
\hline Blepharoptosis (\%) & & 2.76 & 3.57 & 4.35 & 9.75 & 20.36 & 31.77 & 41.99 \\
\hline
\end{tabular}

${ }^{\mathrm{a}} \mathrm{SE}$ means standard error

\section{Blepharoptosis prevalence according to age group and obesity parameters (Figs. 2 and 3 )}

Figure 2 shows blepharoptosis prevalence (\%) according to age and obesity parameters, including BMI and abdominal obesity (WC). The blepharoptosis prevalence was higher among participants with a BMI more than and equal to 25 versus those with a BMI less than 25. Blepharoptosis prevalence was also higher in the participants with a WC more than and equal to $90 \mathrm{~cm}$ (males) and more than equal to $80 \mathrm{~cm}$ (females) versus those with a WC less than $90 \mathrm{~cm}$ (males) and less than $80 \mathrm{~cm}$ (females). Figure 3 shows the association between blepharoptosis and BMI according to age group. In the 50-59 and 60-69 years age groups, blepharoptosis incidence was higher, and the participants had higher BMI scores. The association between blepharoptosis incidence and obesity severity in these groups was stronger than that in the other groups. However, in the 70-79 and 80-89 years age groups, extremely obese participants (BMI more than 30) showed a sudden decrease in the prevalence of blepharoptosis.

\section{Optimal cutoff age for recommending blepharoptosis evaluation (Fig. 4)}

Finally, we investigated the cutoff age of for recommending blepharoptosis evaluation. The cutoff age in the prediction of blepharoptosis was defined as the point of largest statistical values using the Rao-Scott chi-square test. Figure 4 shows that the optimal cutoff age was 66 years for all participants, 63 years for males, and 71 years for females.

\section{Discussion}

This study suggested that among the general Korean population, evaluation for blepharoptosis was recommended for the total population, males, and females at 66 years, or at 63 and 70 years for males and females, separately. The estimated prevalence of blepharoptosis in our study was $12.08 \%$. This result is consistent with previous reports. Among Korean adults aged more than 40 years, the prevalence rate of age related blepharoptosis was $13.5 \%$ [15]. An estimated $11.5 \%$ of adults in the UK aged more than 55 years had blepharoptosis [16]. Thapa et al. reported in a hospital-based, cross-sectional study conducted in Nepal that $10.7 \%$ of ptosis cases were of aponeurotic ptosis [17].

Moderate to severe blepharoptosis can impair visual function (e.g., loss of superior visual fields) [6] cause psychological distress (e.g., anxiety and depression) [5], reduce health-related quality of life [18], and cause tension-related headaches [7-9]. Blepharoptosis in older adults may be underestimated or ignored because both 


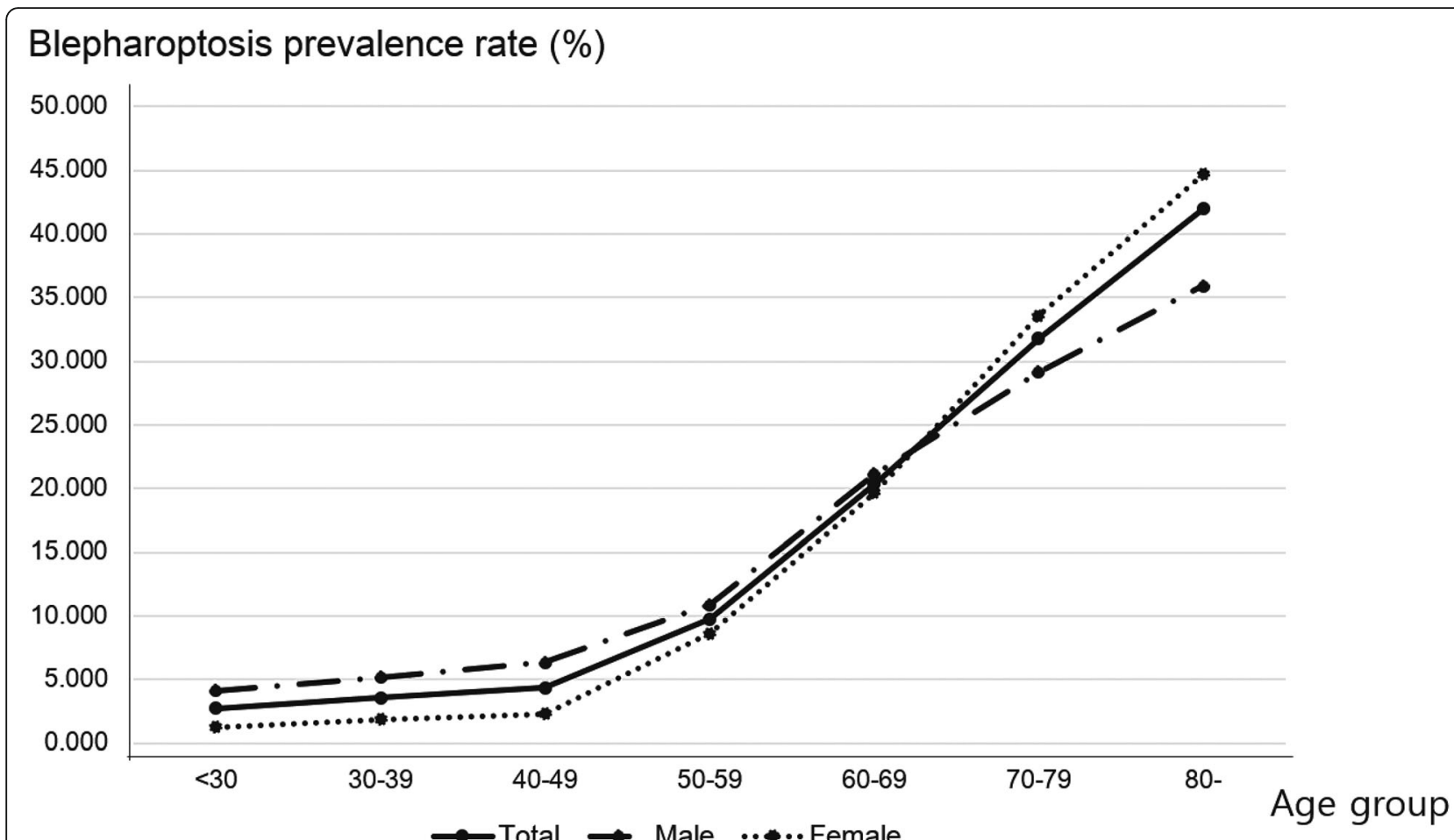

Fig. 1 Prevalence of blepharoptosis among Korean males, females, and the total population according to age. The prevalence of blepharoptosis increased with age for all three groups

physicians and patients consider the condition to be a result of the aging process. However, surgical repair of involutional blepharoptosis is not a difficult process, and most cases can be easily repaired under local anesthesia within a few hours [12]. Health-related quality of life outcomes are becoming increasingly important in determining the allocation of healthcare resources, and identifying these outcomes allows clinicians to better inform patients. Determination of an age cutoff for blepharoptosis evaluation is therefore important for patients and

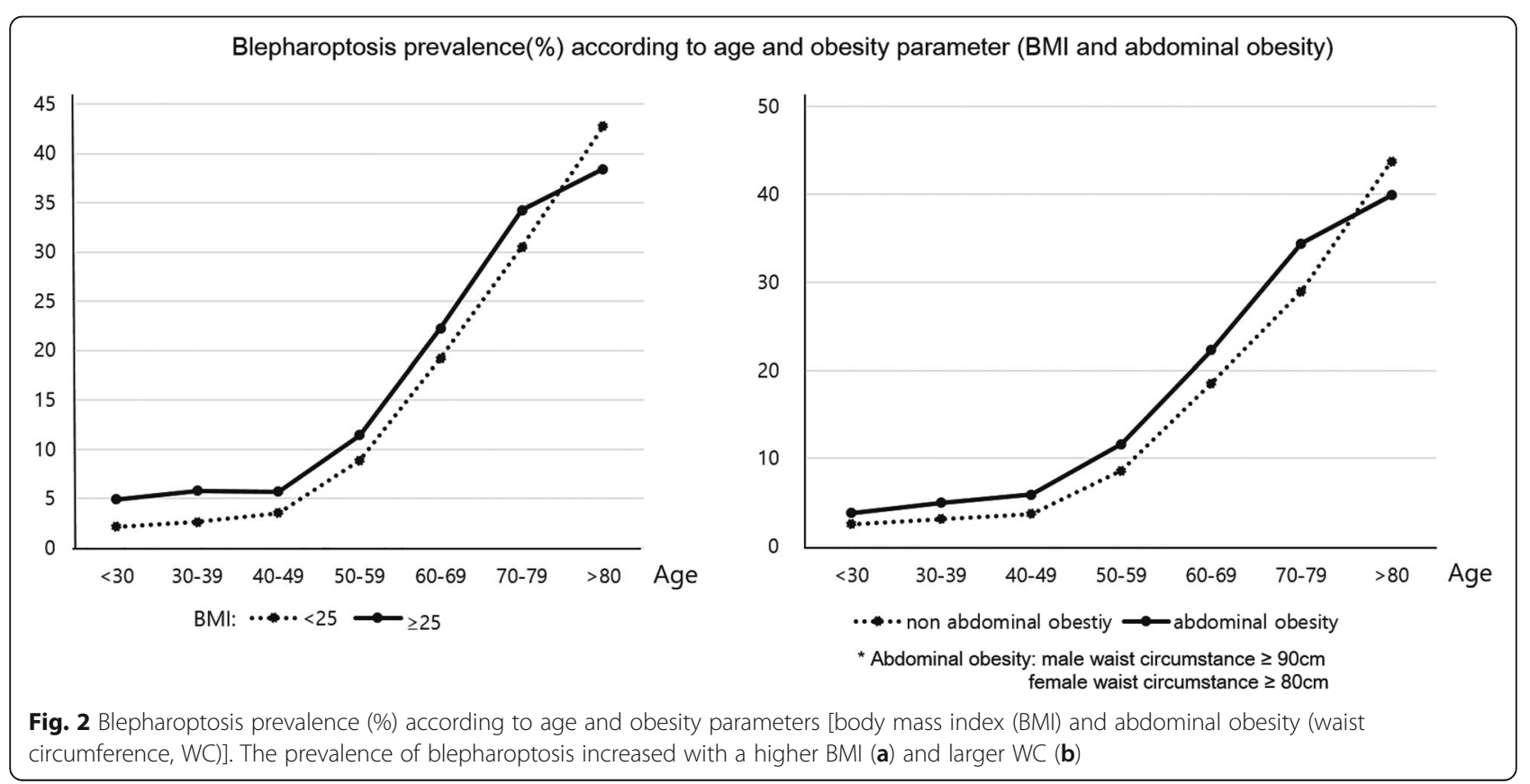




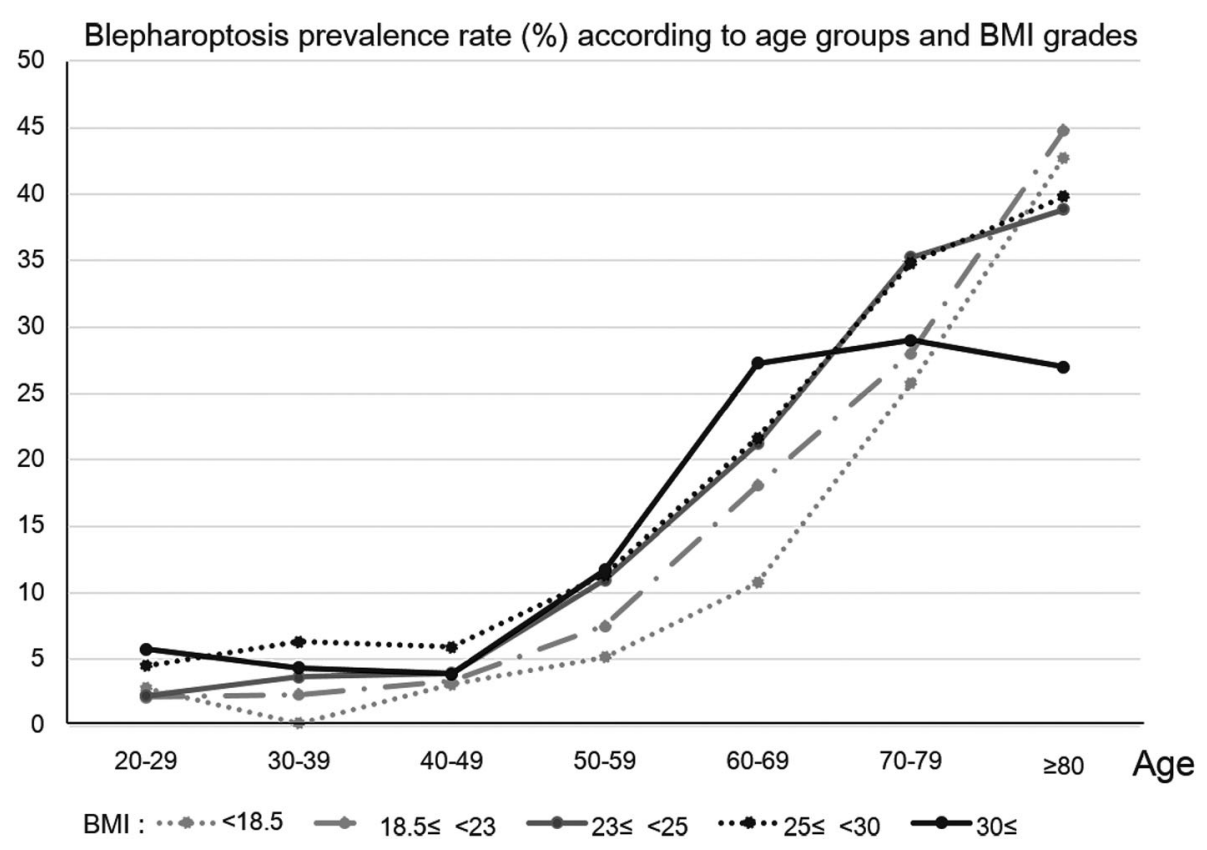

Fig. 3 Blepharoptosis prevalence (\%) according to age group and BMI. In general, the prevalence of blepharoptosis increased with higher BMI, which were more prominent between the 50-59 and 60-69 years of age groups, and between the 60-69 and 70-79years of age groups. However, participants aged more than 70 years and with a BMI more than and equal to 30 were less likely to have blepharoptosis

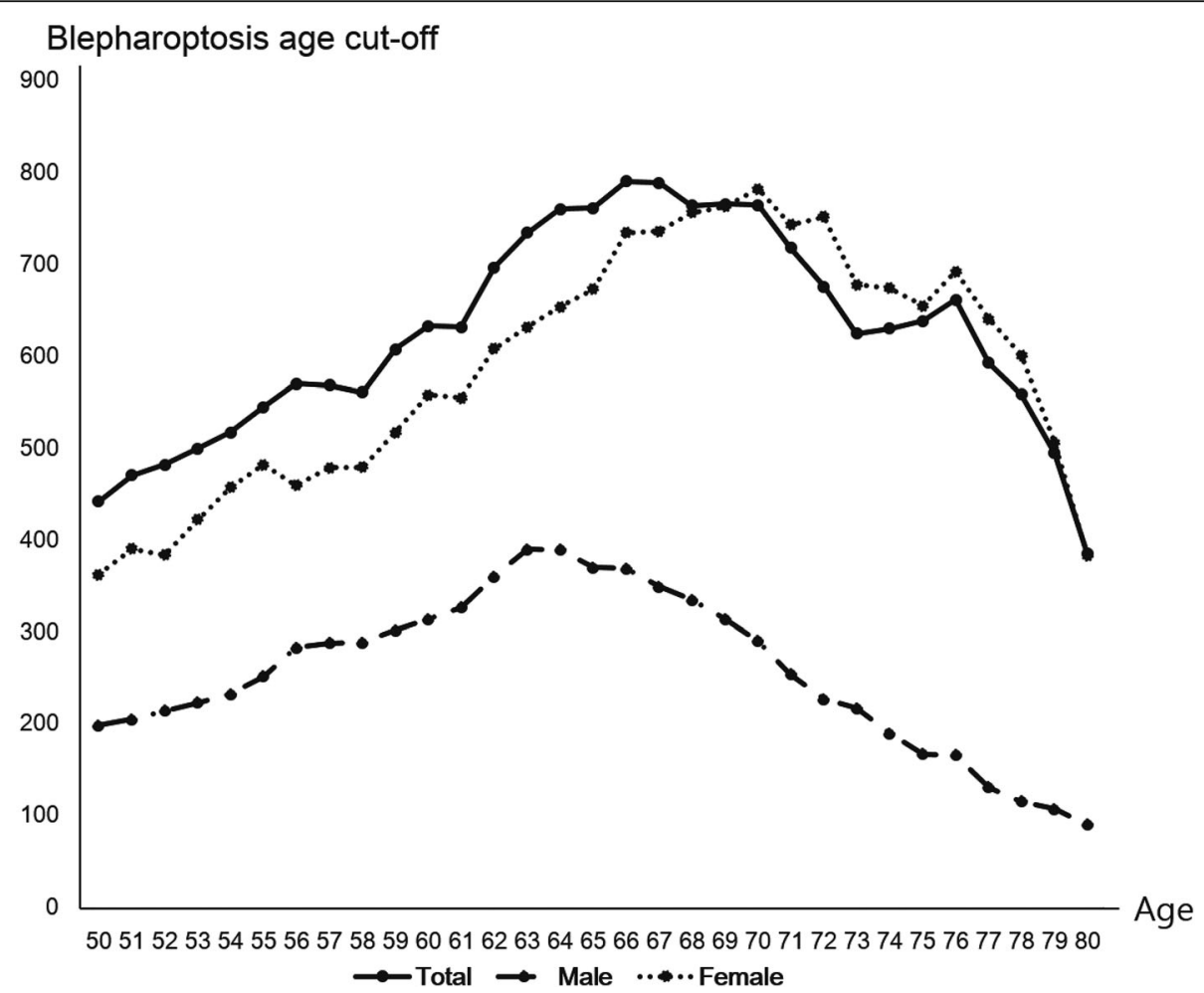

Fig. 4 The cutoff age for recommending blepharoptosis evaluation was 66 years in the total population, 63 years in males, and 71 years in females. The cutoff age used in the prediction of blepharoptosis was defined as the point of largest statistical values using the Rao-Scott chi-square test 
physicians considering the surgical benefits of blepharoptosis repair surgery.

In our study, the prevalence of blepharoptosis increased with age. MRD1 values and LFT scores decreased with age, while the prevalence of blepharoptosis increased. This can be explained by aponeurotic or periorbital changes. Aponeurotic dehiscence or disinsertion is a well-known cause of involutional ptosis [19]. Guyuron and Harvey reported that blepharoptosis and enophthalmos can be caused by periorbital and orbital aging, and there was a strong association between age-related enophthalmos and upper eyelid ptosis, which was undetected [11]. Aponeurotic abnormalities accompanied by orbital and periorbital aging-related changes can therefore cause involutional blepharoptosis, with age itself being one of strongest risk factors for involutional blepharoptosis.

Figures 1 and 2 show that, in this study, more obese participants were more likely to have blepharoptosis. Similarly, Paik et al. reported that obesity parameters (BMI, WC, and percent body fat) were strongly associated with age-related blepharoptosis [20]. However, when comparing blepharoptosis prevalence according to age group and BMI, participants aged more than 70 years and with a BMI more than and equal to 30 were less likely to have blepharoptosis. This might have been due to the exclusion of extremely obese adults aged more than 70 years from the study, on the assumption that they would had other severe medical disorders, or to the survival rate of extremely obese adults aged more than 70 years being lower than that of the younger participants to their higher risk of severe cardiovascular or cerebrovascular disorders [21, 22].

There were some limitations to this study. First, because it used a cross-sectional design, disease causality could not be established from the investigated associations. Second, the study included a nationally representative population of Korean males and females, so our findings may not be generalizable to other populations or racial groups. Finally, because the most important variable, MRD1, was conducted by several inspectors instead of one expert due to the high number of participants, there could be biases among inspectors. In spite of these limitations, this is the first population-based study to measure eyelid parameters in detail, and to determine the cutoff age of age-related involutional blepharoptosis.

In conclusion, this was the largest population-based study to determine the cutoff age for recommending blepharoptosis evaluation from representative data on involutional blepharoptosis among Korean adults. We suggest that for the general population, evaluation for blepharoptosis should be done at 66 years of age, or at 63 and 70 years for males and females, separately. In summary, this study provided appropriate age thresholds for involutional blepharoptosis among the general population of Korea.
The results also suggest that past a certain age, Koreans should undergo regular blepharoptosis evaluations.

\section{Conclusions}

There was astrong association between older age and the prevalence of blepharoptosis. Moderate to severe blepharoptosis resulted in poor visual function and exacerbated headaches and depression, leading to decreased quality of life. This study could suggest that for the general Korean population, evaluation for blepharoptosis should be done at 66 years of age, or at 63 and 70 years of age for males and females, separately.

\section{Abbreviations}

\% SE: \% Standard error; BMI: Body mass index; KNHANES: The Korean National Health and Nutrition Examination Survey; LFT: Levator function test; MRD1: Marginal reflex distance 1; SE: Standard error; USD: United States Dollars; WC: Waist circumference

\section{Acknowledgments}

The authors thank the Korea Centers for Disease Control and Prevention for providing the study data.

\section{Authors' contributions}

JP and $\mathrm{KH}$ designed and analyzed the study and drafted all versions of the manuscript. KN, SJ and SK advised on the design and analyses, and reviewed successive drafts of the manuscript. SY, WC, and YP designed the study and reviewed successive drafts of the manuscript. KH designed certain of the study materials, contributed to the analyses, and analyzed some of the data. All authors have read and approved the manuscript.

\section{Funding}

The Basic Research Foundation of Korea (National Research Foundation, NRF) supported this research, which was funded by the Ministry of Education, Science, and Technology (2016R1D1A1B03930886). The funder had no influence on the design, collection, analysis or interpretation of the data, or in writing the manuscript.

\section{Availability of data and materials}

All data generated and analyzed during this study are included in relevant published articles.

\section{Ethics approval and consent to participate}

The data documentation and representative data analysis was approved by the Korea Centers for Disease Control and Prevention (KCDC). All participants provided written consent forms prior to data collection. All authors discussed with the Epidemiologic Survey Committee of the Korean Ophthalmologic Society regarding correct and accurate analyses of the nationally representative data.

\section{Consent for publication \\ Not applicable.}

\section{Competing interests}

The authors declare that they no competing interests.

\section{Author details}

'Department of Ophthalmology, Yeouido St. Mary's Hospital, College of Medicine, The Catholic University of Korea, Seoul, South Korea. ${ }^{2}$ Department of Biostatistics, The Catholic University of Korea, 222 Banpo-daero,

Seocho-Gu, Seoul 137-701, South Korea. ${ }^{3}$ Department of Ophthalmology and Visual Science, Seoul St. Mary's Hospital, College of Medicine, The Catholic University of Korea, 222 Banpo-daero, Seocho-Gu, Seoul 137-701, South Korea. ${ }^{4}$ Department of Ophthalmology, Daejeon St. Mary's Hospital, College of Medicine, The Catholic University of Korea, Daejeon, South Korea.

${ }^{5}$ Eyeclinc, Center for Clinical Center, National Cancer Center, Goyang-si, South Korea. 
Received: 10 January 2019 Accepted: 18 February 2020

Published online: 13 March 2020

\section{References}

1. Collin JR. Involutional ptosis. Aust N Z J Ophthalmol. 1986;14:109-12.

2. Shore JW, McCord CD Jr. Anatomic changes in involutional blepharoptosis. Am J Ophthalmol. 1984;98:21-7.

3. Ahmadi AJ, Saari JC, Mozaffarian D, et al. Decreased carotenoid content in preaponeurotic orbital fat of patients with involutional ptosis. Ophthalmic Plast Reconstr Surg. 2005;21:46-51.

4. Dortzbach RK, Sutula FC. Involutional blepharoptosis. A histopatholocial study. Arch Ophthalmol. 1980;98:2045-9.

5. Richards HS, Jenkinson E, Rumsey N, et al. The psychological well-being and appearance concerns of patients presenting with ptosis. Eye. 2014;28:296302.

6. Briceño CA, Fuller ML, Bradley EA, Nelson CC. Assessment of the abbreviated National eye Institute visual function questionnaire (NEI VFQ 9) in blepharoptosis and dermatochalasis. Arq Bras Oftalmol. 2016;79:226-8.

7. Matsuo K, Ban R. Surgical desensitization of the mechanoreceptors in Müller's muscle relieves chronic tension-type headache caused by tonic reflexive contraction of the occipitofrontalis muscle in patients with aponeurotic blepharoptosis. J Plast Surg Hand Surg. 2013;47:21-9.

8. Bearden WH, Anderson RL. Corrugator superciliaris muscle excision for tension and migraine headaches. Ophthal Plast Reconstr Surg. 2005;21:41822.

9. Mokhtarzadeh A, McClelland C, Lee MS, et al. The bleph and the brain: the effect of upper eyelid surgery on chronic headaches. Ophthal Plast Reconstr Surg. 2017;33:178-81.

10. BahceciSimsek I. Association of Upper Eyelid Ptosis Repair and Blepharoplasty with headache-related quality of life. JAMA Plast Surg. 2017; 19:293-7.

11. Guyuron B, Harvey D. Periorbital and Orbital Aging: Senile Enophthalmos as a cause of Upper Eyelid Ptosis. Plast Reconstr Surg. 2016;138:31e-7e.

12. Liu D. Ptosis repair by single suture aponeurotic tuck. Surgical technique and long-term results. Ophthalmology. 1993;100:251-9.

13. Shirado M. Dyslipidemia and age-related involutional blepharoptosis. J Plast Reconstr Aesthet Surg. 2012;65:e146-50.

14. Yoon KC, Mun GH, Kim SD, et al. Prevalence of eye diseases in South Korea: data from Korean National Health and nutrition examination survey 20082009. Korean J Ophthalmol. 2011;25:421-33.

15. Kim MH, Cho J, Zhao D, et al. Prevalence and associated factors of blepharoptosis in Korean adult population: the Korea National Health and nutrition examination survey 2008-2011. Eye. 2017;31:940-6.

16. Sridharan GV, Tallis RC, Leatherbarrow B, Forman WM. A community survey of ptosis of the eyelid and pupil size of elderly people. Age Ageing. 1995;24: $21-4$.

17. Thapa R, Karmacharya PC, Nepal BP. Etiologic pattern of blepharoptosis among patients presenting in teaching hospital. JAMA J Nepal Med Assoc. 2006;45:218-22.

18. Battu VK, Meyer DR, Wobig JL. Improvement in subjective visual function and quality of life measures after blephraoptosis surgery. Am J Ophthalmol. 1996;121:677-86.

19. Wouters RJ, van den Bosch WA, Mulder PG, Lemij HG. Upper eyelid motility in the aging eyelid. Invest Ophthalmol Vis Sci. 2001;42:620-5.

20. Paik JS, Jung SK, Han KD, et al. Obesity as a Potential Risk Factor for Blepharoptosis: The Korea National Health and Nutrition Examination Survey 2008-2010. PLoS One. 2015;10:e0131427.

21. Engin A. The Definition and Prevalence of Obesity and Metabolic Syndrome. Adv Exp Med Biol. 2017;960:1-17.

22. Stenholm S, Head J, Aalto V, et al. Body mass index as a predictor of healthy and disease-free life expectancy between ages 50 and 75: a multicohort study. Int J Obes. 2017;41:769-75.

\section{Publisher's Note}

Springer Nature remains neutral with regard to jurisdictional claims in published maps and institutional affiliations.

\section{Ready to submit your research? Choose BMC and benefit from:}

- fast, convenient online submission

- thorough peer review by experienced researchers in your field

- rapid publication on acceptance

- support for research data, including large and complex data types

- gold Open Access which fosters wider collaboration and increased citations

- maximum visibility for your research: over $100 \mathrm{M}$ website views per year

At BMC, research is always in progress.

Learn more biomedcentral.com/submissions 